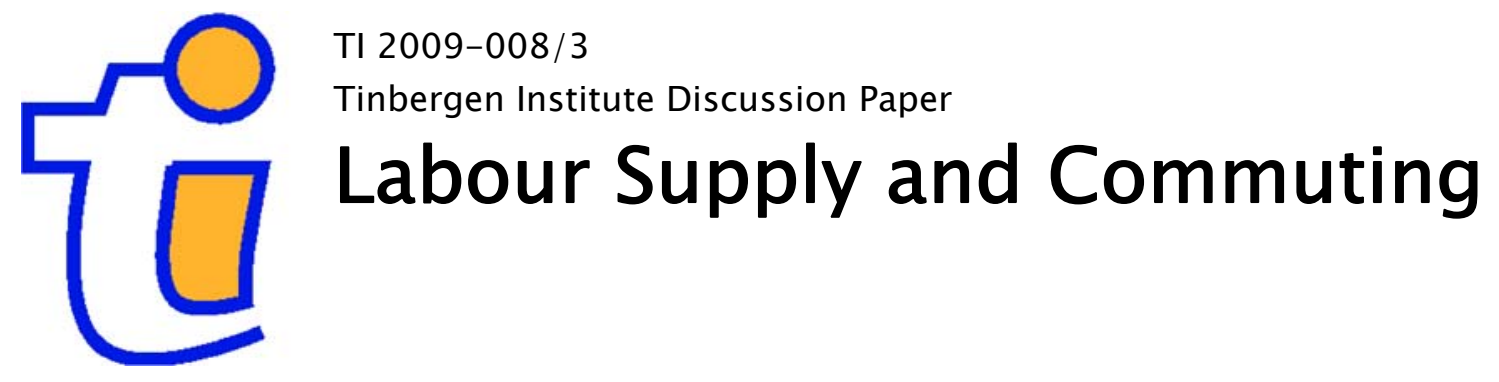

Eva Gutiérrez-i-Puigarnau

Jos van Ommeren

VU University Amsterdam, and Tinbergen Institute. 


\section{Tinbergen Institute}

The Tinbergen Institute is the institute for economic research of the Erasmus Universiteit Rotterdam, Universiteit van Amsterdam, and Vrije Universiteit Amsterdam.

Tinbergen Institute Amsterdam

Roetersstraat 31

1018 WB Amsterdam

The Netherlands

Tel.: +31(0)205513500

Fax: $+31(0) 205513555$

Tinbergen Institute Rotterdam

Burg. Oudlaan 50

3062 PA Rotterdam

The Netherlands

Tel.: + $31(0) 104088900$

Fax: $+31(0) 104089031$

Most TI discussion papers can be downloaded at http://www.tinbergen.nl. 


\title{
LABOUR SUPPLY AND COMMUTING: IMPLICATIONS FOR OPTIMAL ROAD TAXES
}

\author{
30-01-2009 \\ Eva Gutiérrez-i-Puigarnau \\ VU University, De Boelelaan 1105, 1081 HV Amsterdam, The Netherlands \\ egutierrez@feweb.vu.nl \\ Jos van Ommeren \\ VU University, De Boelelaan 1105, 1081 HV Amsterdam, The Netherlands \\ jommeren@feweb.vu.nl
}

\begin{abstract}
A new paradigm for transport economists has been established: revenues of a welfaremaximising road tax should be employed to reduce the level of a distortionary income tax. An essential modelling assumption to reach this conclusion is that the number of workdays is optimally chosen, whereas daily workhours are fixed, implying that given a road tax, workers may only reduce their commuting costs by reducing total labour supply. However, a labour supply model which also allows for optimally chosen daily hours implies that commuting costs increase daily hours, whereas the effect on total labour supply is ambiguous. This paper addresses this issue empirically by analysing the relationship between labour supply patterns and commuting distance using the socio-economic panel data for Germany between 1997 and 2007. Endogeneity of commuting distance is accounted for by using employer-induced changes in commuting distance. In line with the theoretical model developed, we find that commuting distance has a positive effect on daily hours. Our analysis does not find a negative effect of commuting distance on total labour supply, suggesting that a reduction in the income tax, as advocated in the literature, may not be necessary.
\end{abstract}

Keywords: Commuting cost, congestion tax, labour supply

JEL codes: J22, R41

The data used in this paper was made available to us by the German Socio-Economic Panel Study (GSOEP) at the German Institute for Economic Research (DIW Berlin). Jos van Ommeren is affiliated to the Tinbergen Institute, Amsterdam, The Netherlands. 


\section{Introduction}

Commuting is one of the main contributors to road congestion. Policymakers may influence the workers' commute to address congestion by introducing a road tax, which concerns a sizeable number of economists (see e.g. Parry and Bento, 2001; De Borger and van Dender, 2003). The textbook analysis of congestion pricing implies that the welfare in the economy does not depend on how the revenue of the road tax is redistributed into the economy (see e.g. Small and Verhoef, 2007, p. 120). This result is obtained under the assumption that the demand and supply of transport is not distorted by other taxes. In case of commuting, it seems reasonable to assume that the labour supply decision of workers is distorted by an income tax such that workers supply less labour than would be the case given the absence of a distortionary income tax (e.g. Bovenberg and Goulder, 1996; Parry and Bento, 2001; Mayeres and Proost, 2001; Calthrop, 2001). If it is the case that road pricing further reduces labour supply, a road tax may even have a negative effect on welfare (Parry and Bento, 2001). One of the main consequences is that to increase welfare in the economy, the revenues of road pricing should be used to reduce the level of the distortionary income taxes (Parry and Bento, 2001). Therefore, if one accepts that total labour supply in the economy is reduced by an income tax, the empirical question is to what extent labour supply is further reduced by a road tax. We do not observe road taxes in most parts of the world but one may examine how an increase in commuting distance affects labour supply, which gives insight into the effect of a road tax on labour supply. This paper address this issue by analyzing the relationship between labour supply patterns and commuting distance using the socio-economic panel data for Germany between 1997 and 2007.

The empirical literature in economics that deals with the relationship between commuting behaviour and the workers' labour supply is closely related to the theoretical literature. Theoretical urban models essentially assume that the residence location is endogenous (e.g. Wales, 1978; White, 1988), whereas labour models assume that it is given (e.g. Gubits, 2004). ${ }^{1}$

\footnotetext{
${ }^{1}$ Urban models assume that commuting distance is optimally chosen based on an optimal choice of the residence taking (endogenously determined) house prices into account, so that workers are fully compensated for longer
} 
In the theoretical section, we keep residence location given in the spirit of labour economics models, and we consider exogenous changes in the commuting distance. In the empirical section however, we deal with the endogeneity of commuting distance, consistent with urban models.

To understand the effect of exogenous changes in commuting costs on changes in labour supply, it is useful to examine the work by labour economists who focus on the optimal setting of number of workhours for workers. Although it is common that theoretical and empirical research focuses on one measure of labour supply (e.g. hours per week), some studies have focused on more flexible specifications of labour supply patterns (e.g. working weeks per year and working hours per week; see e.g. Hanoch, 1980, p. 119; Blank, 1988). One important issue is then the presence of fixed costs of work, such as commuting costs, which are costs that are not related to the amount of labour supplied. Cogan (1981) establishes that when fixed costs of work are present, the period of time over which the fixed costs are incurred is the ideal measure of labour supply. That is, if fixed costs of work are per day, such as daily commuting costs, and these daily costs are important, then the appropriate measure of labour supply is daily labour supply. ${ }^{2}$ Cogan (1981), and subsequently textbooks in labour economics (e.g. Ehrenberg and Smith, 2003), assume that the number of workhours is optimally chosen given the commuting distance, which implicitly implies that labour supply is optimally chosen per day. ${ }^{3}$

In contrast, Parry and Bento (2001) make the opposite assumption by assuming that workers optimally choose their number of workdays, whereas daily hours are fixed. This assumption is nowadays standard in the transport literature on labour supply and commuting (e.g. Calthrop, 2001). The number of workdays per week determines then the total commuted distance per week (the distance between the residence and the workplace times the number of

commutes by lower house prices. Static labour models usually assume that the number of workhours is optimally chosen given the commuting distance, and workers are not compensated by higher wages.

${ }^{2}$ Cogan (1981), as a response to the seminal paper by Heckman (1980), examines the effect of labour costs on labour supply. Although theoretically he cannot provide a clear answer whether this effect on total labour supply is positive or negative, empirically he concludes that increases in daily fixed costs of work will reduce labour supply, at least for the sample of mature women that he analyses.

${ }^{3}$ In this literature, slightly confusingly, it is not discussed explicitly whether labour supply is per day or per week, but since the commuting costs are considered fixed, labour supply must be per day. This literature then shows that workers optimally choose a minimum but positive number of daily hours. 
workdays). Consequently, there is a strict complementarity between the commuted distance per week and total labour supply. ${ }^{4}$ This assumption simplifies the analysis of the effect of commuting costs on labour supply, but implies that, conditional on the choice of transport mode, given an increase in commuting costs, e.g. due to a road tax, workers may only reduce their commuting costs by reducing their total labour supply. ${ }^{5}$ It is then intuitive that a road tax that increases commuting costs may reduce welfare given the presence of a distortionary income tax. Recycling the road-tax revenues by reducing the levels of income tax will then increase welfare (as demonstrated by Parry and Bento, 2001)

Arguably, workers have other behavioural margins than a reduction in labour supply to reduce their commuting costs, so the revenue-recycling argument may not hold in a more general setting. This is relevant as the other behavioural margins are not, or at least not systematically, distorted by the income tax. We will discuss here three relevant behavioural margins that are discussed in the literature. First, workers have quite some flexibility with respect to the chosen workhours (see e.g. Arnott, 2005, p. 135). Particularly in congested areas, workers may leave earlier, or later, from home, in order to avoid peak hours (Arnott et al., 1993). Second, workers may change commuting costs by moving residence (Gubits, 2004). Third and this will be the focus of the current paper, workers have the option to increase the number of hours worked per day and, maybe simultaneously, decrease the number of workdays. ${ }^{6}$ Hence, in a more general setting than usually assumed, the effect of an increase in average commuting costs (induced by a road tax) on total labour supply may be negligibly small, or, as we will see, even positive.

As far as we are aware, this is the first study that distinguishes theoretically and empirically between number of workdays and daily labour supply. In the theoretical model, it is

\footnotetext{
${ }^{4}$ With strict complementarity we mean that a change in labour supply implies a proportional change in the distance travelled (e.g. per week). See also Wuyts (2009) who allows for telecommuting and therefore does not assume complementarity.

${ }^{5}$ Given this assumption, in order to measure the effect of commuting costs on labour supply, it is reasonable to employ empirical labour supply elasticities that are based on the estimated relationship between labour supply and wages (see Parry and Bento, 2001, who use these supply elasticities to calibrate their model). Note that if this assumption does not hold, then to employ these elasticities may be incorrect.

${ }^{6}$ As already noted by Hamermesh (1996) for Germany, the variation in daily hours is slightly larger than the variation in days, suggesting that this mechanism is important.
} 
assumed that both daily hours and number of workdays (e.g. per week) are optimally chosen by workers. It is shown that (monetary and time) commuting costs increase daily hours. This is a relevant result, as it implies that it may be an important behavioural margin that, given a road tax, workers increase their daily hours. It also follows that workers may react quite differently to an increase in monetary commuting costs than to a decrease in wages. Furthermore, it is shown that commuting time reduces workdays. The effect of commuting time and monetary commuting costs on total labour supply is ambiguous, as it is not clear a priori whether the effect on daily hours or workdays dominates.

In the empirical section, we examine the effect of commuting distance on labour supply patterns, distinguishing between total labour, daily labour supply and number of workdays, where daily labour supply is defined as the number of workhours per day. ${ }^{7}$ We employ commuting distance as a proxy for a combination of monetary and time commuting costs. One of the main issues we are concerned with is that commuting distance may be endogenous with respect to labour supply patterns. We use therefore a worker first-differences approach and employ an approach where changes in commuting distance are employer-induced, and therefore exogenous. ${ }^{8}$

In the next section, we discuss the theoretical setting. The remainder of the paper is structured as follows: section 3 provides information on the data employed, introduces the econometric model and presents the empirical results. Section 4 concludes.

\section{The Model}

To explain the labour supply behaviour of employed individuals, we introduce a labour supply model including commuting. ${ }^{9}$

\footnotetext{
${ }^{7}$ In empirical studies known to us, labour supply is measured per week or even longer period (one exception is Hamermesh, 1996).

${ }^{8}$ In the literature it is emphasized that it is difficult to find an instrument for commuting distance to correct for possible endogeneity (see e.g. Manning, 2002). For an attempt to instrument commuting distance, see Gubits (2004). ${ }_{9}^{9}$ We ignore income taxes, which obviously affect the net wage, as well as road taxes, which directly affect the monetary and indirectly the time costs of commuting (through reduced congestion). Introducing these taxes, as well
} 


\subsection{Theory}

We assume a standard labour supply model, but extend this model by allowing for commuting costs and by distinguishing between daily work time and number of workdays. For an individual who participates in the labour market there are two essential decisions to be made each period (e.g. defined by a week or a year): (i) how much work-time per day, $H$, and (ii) how many days, $D$, she would like to work. So, total labour supply per period is defined by $D H$. The number of days $D$ and daily work time $H$ are assumed to be continuous variables. ${ }^{10}$ It is assumed that the labour supply preferred by employed individuals can also be realized. Participation in the labour market implies that $D H>0$, so that $H>0$ and $D>0$. In line with the literature, we assume that commuting involves time $t$ and induces monetary commuting costs. The monetary costs are proportional to distance $k$ with a positive cost per kilometre $c$ and are therefore equal to $k c .^{11}$

Suppose that workers derive utility from income $Y$ and leisure time $L$, and that there are only two possible uses of time: labour and leisure. The workers' utility function $v$ can then be written as $v=V\left(Y_{0}+w(H) D-D k c, \bar{L}-D H-D t\right)$, where $\bar{L}$ is the worker time endowment per week (or maximum leisure time), $Y_{0}$ is non-labour income and $w(H)$ is the daily wage, which depends on the number of daily hours worked. Total income (net of monetary commuting costs) and leisure time are formulated as $Y=Y_{0}+w(H) D-D k c$ and $L=\bar{L}-D H-D t$. We assume that the daily wage is increasing and concave in $H$. So, $w^{\prime}(H)>0$ and $w^{\prime \prime}(H)<0$, where $w^{\prime}(H)$ denotes the marginal effect of $H$ on the wage. ${ }^{12}$ The utility function $v$ is assumed to be twice-

as government budget restrictions, is necessary for welfare analyses (Parry and Bento, 2001). In the current paper however, we are mainly concerned with the effect of changes in commuting costs on labour supply, so we abstract from taxation issues.

${ }^{10}$ If the period is a year, it is clear that the number of days is continuous. If it is a week, then the assumption that the number of days is continuous is still plausible if the worker is able to vary the number of days per week over time. For example, let us suppose that an individual prefers to work 1.2 days per week. She will work one day per week for a period of four weeks and the fifth week she will work two days.

${ }^{11}$ In our analysis, commuting speed is exogenously given. For an analysis with endogenous speed, see for example, Van Ommeren and Fosgerau (2009).

${ }^{12}$ Concavity of the daily wage can be justified when the employer pays the worker's marginal productivity and a worker becomes less productive the more hours she works. 
differentiable and concave. ${ }^{13}$ This assumption is reasonable when income and leisure are both normal goods. When $D H>0$, then $w(H)>k c$, so participation in the labour market implies that the daily wage exceeds the daily monetary commuting costs.

Using standard microeconomic techniques (see e.g. Varian, 1992), we derive the workers' optimally chosen daily work time $H$ and days $D$ by maximising $v$, implying the following two first-order conditions:

$$
V_{Y} w^{\prime}(H) D-V_{L} D=0,
$$

and

$$
V_{Y}[w(H)-k c]-V_{L}[H+t]=0 .
$$

The first condition (1) states that the worker's marginal utility of leisure time equals the marginal opportunity cost of leisure time. The second condition (2) states that the worker's marginal utility of working one day equals the marginal opportunity costs of working one day. ${ }^{14}$ Given these two first-order conditions, the optimally chosen daily work time is defined by:

$$
w^{\prime}(H)[H+t]=w(H)-k c .
$$

To interpret (3), note that the right-hand side of this expression states that the worker's marginal cost of working one day (marginal opportunity cost of leisure times the loss of leisure time) is equal to the daily wage net of monetary commuting costs. Given (3), it follows immediately that monetary commuting costs $k c$ and commuting time $t$ increase the daily work time $H^{15}$

In Appendix A, we elaborate further on the effects of exogenous changes in monetary commuting costs $k c$ and commuting time $t$ separately on the optimally chosen number of days $D$

\footnotetext{
${ }^{13}$ So, the first derivatives are positive, the second derivatives are negative and the cross-derivatives are positive.

${ }^{14}$ In Appendix A, it is shown that the second-order conditions are fulfilled.

$15 \partial H / \partial t=-w^{\prime}(H)^{2}\left[[w(H)-k c] w^{\prime \prime}(H)\right]^{-1}>0 ; \partial H / \partial(k c)=-\left[w^{\prime \prime}(H)[H+t]\right]^{-1}>0$. Clearly, in our model, the qualitative effect of $k c$ is the same as the effects of $k$ and $c$.
} 
and total labour supply $\mathrm{DH}$. We proceed in two ways. First, we examine the (partial) effects of increases in commuting time $t$, as well as monetary commuting costs $k c$. Second, we consider the case that a change in commuting distance implies an equivalent increase in commuting time. This case essentially allows us to understand the overall effect of distance when workers face a constant commuting speed. The overall effect of distance on labour supply involves then effects through an increase in commuting time and monetary commuting costs. This is relevant as in our empirical analysis, we observe commuting distance, but are not able to distinguish between the effect of commuting time and monetary commuting costs separately.

We find that an increase in commuting time decreases $D$, whereas the effect of a change in $t$ on total labour supply $D H$ turns out to be ambiguous. Given an increase in daily commuting time $t$, workers will reduce their overall commuting time by reducing the number of workdays, but they will also react by increasing daily labour supply. Which of the two effects dominates is an empirical matter and cannot be derived from our model. The effect of monetary costs on $D$ can be shown to be ambiguous. The ambiguity is due to that the income effect of an increase in monetary costs may dominate the substitution effect. Furthermore, it appears that the effect of a change in $k c$ on total labour supply is also ambiguous.

When we assume that a change in commuting distance also implies an equivalent change in commuting time (as speed is constant), we find that an increase in monetary costs also increases $H$, but the effects on $D$ and $D H$ are ambiguous. To see the ambiguity on $D H$, similar reasons to the effect of monetary costs on $D H$ apply.

\subsection{Total labour supply constant}

We are also interested in the effect of a marginal increase in commuting costs on workdays and daily work time, keeping the total labour supply DH constant. This allows us to test some additional predictions of the model. Furthermore, this allows us to examine the behaviour of workers that are constrained by their employer to keep total labour supply constant. Constraints 
by employers are quite common (see later on). ${ }^{16}$ Utility $v$ can then be rewritten as $v=V\left(Y_{0}+w(x / D) D-D k c, \bar{L}-x-D t\right)$, where $x=D H$ is given. The first-order conditions for $D$ and $X$ imply $v_{Y}\left[w(x / D)-k c-w^{\prime}(x / D) x / D\right]-v_{L} t=0$ and $v_{Y} w^{\prime}(x / D)-v_{L}=0$. The first-order conditions together imply that $w^{\prime}(x / D)[x / D+t]=w(x / D)-k c$, which is identical to (3) and implies that $\partial H / \partial(k c)>0 .{ }^{17}$ Further, rather obviously, conditional on total labour supply, differentiating the first-order condition implies $H[\partial D / \partial(k c)]+D[\partial H / \partial(k c)]=0$, which can be rewritten as $\partial D / \partial(k c)=-[D / H][\partial H / \partial(k c)]$. So, $\partial \log (D) / \partial(k c)=-\partial \log (H) / \partial(k c)$. Hence, in the empirical application, when we control for total labour supply, it is not only convenient to use logarithms of $D$ and $H$, but, given a correct specification of the model, it is arbitrary to focus on $\log H$ or $\log D$.

\subsection{Overview of the model and literature}

A comparison of our theoretical results with those obtained in the literature is given in Table 1 . The labour literature, such as Cogan (1981), assumes that workers optimally chose their daily labour supply, whereas the number of workdays is fixed. This literature indicates that daily hours (and therefore total labour supply) decline with an increase in commuting time (see e.g. Manning, 2003; Gubits, 2004). In contrast, an increase in monetary costs of commuting leads to an increase in daily hours and weekly labour supply (Cogan, 1981; Gubits, 2004).

On the other hand, transport economists, such as Parry and Bento (2001), make the opposite assumption, implying that commuting time decreases days as well as total labour supply, whereas the effect of monetary costs of commuting is ambiguous. Based on assumptions regarding the size of the income and substitution effect, the authors presume that if monetary

\footnotetext{
${ }^{16}$ For example, in the Netherlands, civil servants may choose from a flexible supply pattern keeping the labour supply constant (e.g. work four days per week at nine hours per day, or work four days at eight hours and one day at four hours).

${ }^{17}$ Interestingly, keeping $D H$ constant derives the same quantitative effects of $k c, t$ or $k$ on $H$ as obtain obtained in the previous section, where we did not control for (the optimally chosen) total labour supply. The same applies on $D$. These results are consistent with the envelope theorem. In contrast, the effects of $k c, t$ or $k$ on the optimally chosen days depend on whether or not condition on $D H$. These results are also consistent with the envelope theorem, as the parameters $k c, t$ or $k$ enter the utility function $v$ but do not enter the constraint of a constant labour supply.
} 
costs increase, total labour supply decreases. ${ }^{18}$

In the current paper, we have relaxed the assumptions regarding days and daily hours. As explained above, we find that daily hours increase with commuting time, whereas days decrease (in contrast to the 'labour supply literature' that obtains the opposite result, and inconsistent with the 'transport literature' that keeps daily hours constant). Furthermore, daily hours increase with monetary commuting costs (consistent with the labour supply literature), but the effect of monetary costs on total labour supply turns out to be ambiguous in our model.

The above results indicate that the impact of an increase in monetary costs on total labour supply is either positive or ambiguous depending on the assumptions made with respect to whether days and daily hours are fixed or optimally chosen, whereas the effect of an increase in time costs on total labour supply is either negative or ambiguous. Introduction of a road tax will reduce the time of commuting trips, but increase the monetary commuting costs. Based on our theoretical model, it cannot be excluded that labour supply will increase given a road tax.

\section{Labour Supply Analysis}

\subsection{The data}

Our empirical study is based on information from the German Socio-Economic Panel (GSOEP) for the years 1997-2007. For each year, we have information on commuting distance as well as on labour supply per week, and for eight years we also have information on daily hours and workdays per week. ${ }^{19}$ As stated in the introduction, we employ commuting distance as a proxy

\footnotetext{
18 The authors assume that $w_{H}=w H$, which implies that $\partial V / \partial w=-\partial V / \partial c$ and $\partial V / \partial \bar{w}=-(\partial V / \partial c) H$. In our model this property does not hold as $H$ can be optimally chosen, resulting in $\partial V / \partial w_{H}=-(\partial V / \partial c) H$. Within the framework of Parry and Bento it makes sense to assume that commuting distance is the minimum commuting distance of all jobs that are available in the economy, so workers cannot adapt commuting distance. One simple way of thinking about this, which is likely closer to reality, is to assume that the residence location is exogenously given and that workers search over space for jobs, where jobs differ in terms of number of daily hours supplied and the length of the commute to the residence. Given this assumption, workers with large marginal opportunity costs of work will both work fewer daily hours as well end up with shorter commuting distances.

${ }^{19}$ For the years 1998, 2001 and 2003, information on daily hours and workdays per week is missing. Note that the number of workdays is not necessary the same as the number of days the worker commutes. For the years 1997, 1999 and 2000, information about the commuting distance is only available if the workplace municipality differs from the residence municipality, so the exact commuting distance is unknown for workers who commute to a workplace location within the residence municipality. This is unproblematic as distances of workers who live and
} 
for a combination of monetary and time commuting costs.

\subsection{Selection of sample and descriptive statistics}

We focus on samples of employees working outside their house. ${ }^{20}$ The analyses are based on a dataset of 43,694 annual observations for 14,034 employees. On average, each employee is observed three times. The data includes demographic information on age, gender, workplace region, net hourly wage, net household monthly earnings, household members and children. Data on workhours per week refer to all hours worked, including overtime. In our data, we have information about the number of days usually worked per week for workers for whom the number of workdays per week is fixed (so it does not change from week to week). This applies to the large majority of workers ( $89 \%$ of all workers). In the results shown, we will treat the number of days as a continuous variable, but treating the number of days as a discrete variable (e.g. 4, 5 or 6 days) generates identical results. ${ }^{21}$ The mean one-way daily commuting distance for all workers in the period of analysis was $15 \mathrm{~km}$ in line with a range of other studies. Consistent with observations that the average commuting distance increases over time, we find that, on average, commuting distance increases $0.1 \mathrm{~km}$ per year.

In Appendix B, Table B1 shows patterns of workhours per day and workdays for the years that these data are available. $84 \%$ of the workers work exactly five days per week, which seems clearly the 'norm'. Only $8 \%$ of the workers work more than five days and only $7 \%$ less than five days. These percentages suggest that either employers restrict the number of workdays or there is little variation in preferences of workers. ${ }^{22}$ In contrast, there seems to be much more variation in

work in the same municipality do not vary much. Hence, for these years, we have imputed a value of $5 \mathrm{~km}$ for workers who live and work in the same municipality. A sensitivity analysis shows that the results presented later on are insensitive to the imputed value (e.g. 0 or $6 \mathrm{~km}$ ). This makes sense as the imputation refers to only $26 \%$ of the observations, and the difference between the (unobserved) distance and the imputed distance is small (less than $10 \%$ of the mean commuting distance).

${ }^{20}$ In order to exclude extreme outliers, the sample is restricted to those workers who work at least two hours per day and maximally 100 per week.

${ }^{21}$ Worker changes in workdays are quite common. In our data, on average, about $16 \%$ of workers change their number of workdays.

${ }^{22}$ In Germany, labour supply has become slightly more flexible over time: the proportion of individuals working exactly five days has fallen over time ( $86 \%$ in 1997 vs. $83 \%$ in 2007). As the drop is only slight, this seems to justify 
workhours per day. For example, only $35 \%$ of all workers work exactly eight hours. This suggests that the fundamental assumption made by studies such as Parry and Bento (2001) and Calthrop (2001) that the number of workdays is optimally chosen whereas the daily hours are fixed may be less appropriate, at least for Germany. It appears also that there is large difference in the distribution of workdays and daily hours between males and females, which suggests that the effect of commuting costs on labour supply may potentially differ by gender.

The correlation coefficient between days and daily hours is 0.22 (see Table B2). The correlation between daily hours and weekly hours is positive and significant at 0.90 , and much larger than the correlation between days and weekly hours at 0.59 . These correlations suggest that variation in the daily hours is more important than variation in days in determining variation in weekly labour supply. ${ }^{23}$

\subsection{Econometric model}

In our empirical application we aim to investigate whether changes in commuting distance influence labour supply patterns, measured by weekly labour supply, number of workdays and daily hours. Let $Z_{i t}$ denote either weekly labour supply, number of workdays or daily hours for a worker $i$ in a specific residence and with a specific employer in year $t$, so $i$ refers to a specific worker-residence-employer combination. Defining worker $i$ in this way will be useful to address endogeneity of commuting distance. Following the labour supply literature, we assume a double$\log$ labour supply specification: ${ }^{24}$

$$
\log Z_{i t}=\alpha_{0}+\alpha_{1} \log k_{\mathrm{it}}+\alpha_{2} X_{i t}+\varepsilon_{i}+u_{i t}
$$

where $\alpha_{1}$ is the elasticity of labour supply $Z_{i t}$ with commuting distance $k_{i t}$, the matrix $X_{i t}$ includes time-varying controls for household characteristics (e.g. children) and work characteristics (e.g.

our procedure to pool the data for the different years. This slight drop is in line with the observation that Germany seems to be moving towards a more flexible labour market (Ostner et al., 2003; Hamermesh, 1996).

${ }^{23}$ These results are in line with the results of Hamermesh (1996).

${ }^{24}$ For example, see Borjas (1980), Costa (2000) and Bell and Freeman (2001). 
net hourly wage rate), which are assumed to be exogenous factors, and $\varepsilon_{i}$ is unobserved heterogeneity, which captures time-invariant unobserved characteristics that are specific to a worker-residence-employer combination. For example, these characteristics may be unobserved worker-specific preferences with respect to $Z$ (e.g. a preference for leisure time), or they may be unobserved residence-specific characteristics (in particular, residence location) or employerspecific characteristics that affect $Z$ (e.g. industry). The particular definition of worker $i$ implies that when a worker changes from residence $i$ to residence $i$, then $\varepsilon_{i \neq} \varepsilon_{i}$. The same holds for changes in employer. We treat $\varepsilon_{i}$ as a fixed parameter and estimate all models in terms of firstdifferences, that is, variables are formulated as changes from one time period to another. Taking first-differences essentially removes $\varepsilon_{i}$ from expression (4) and implies that:

$$
\log \left(Z_{i t}\right)-\log \left(Z_{i t-1}\right)=\alpha_{1}\left[\log \left(k_{i t}\right)-\log \left(k_{i t-1}\right)\right]+\alpha_{2}\left[X_{i t}-X_{i t-1}\right]+v_{i t},
$$

where $v_{i t}=u_{i t}-u_{i t-1}$. Consistent estimation of $\alpha_{1}$ requires that the change in commuting distance, $\log \left(k_{i t}\right)-\log \left(k_{i t-1}\right)$, is exogenous to $\log \left(Z_{i t}\right)-\log \left(Z_{i t-1}\right)$ and therefore not related to $v_{i t}$. This may not be the case, since a change in the workers' commuting distance may be the result of an endogenously chosen residence or job move. However, the change may also be the result of workplace relocation when staying with the same employer. The latter type of relocation can be argued to be exogenous, in particular in the case of a firm relocation (when all workers in the firm's establishment are moved to another workplace location). In (5), only within-workers' variation in variables for each worker given the same residence and the same employer is employed in the estimation procedure. Thus, the effect of distance on $\log \left(Z_{i t}\right)-\log \left(Z_{i t-1}\right)$ relates purely to changes in commuting distance for a given residence and a given employer, so that reverse causation is eliminated, and $\alpha_{1}$ provides a consistent estimate of the effect of commuting distance on labour supply. ${ }^{25}$ Keeping the workers' residence and employer constant as we do,

\footnotetext{
25 The estimation of a worker-residence-employer first-differences model is similar to an estimation of (5) on a selective sample of workers who do not change of residence and stay with the same employer. Information of
} 
any observed change in a worker's commuting distance must be employer-induced (due to a firm relocation) or may also be due to measurement error. ${ }^{26}$

The idea to use firm relocation as a source of exogenous change in commuting distance is also exploited in Zax (1991) and Zax and Kain (1996). Firm relocations are quite common and are therefore a useful source of variation in commuting distance. For example, about 7-8\% of firms in the Netherlands are each year involved in relocation decisions (Weltevreden et al., 2007). In Great Britain, in each year $0.5 \%$ of workers state that they change residence because of a firm-induced workplace move, suggesting that workplace moves are quite important, as only a (small) proportion of workers would move residence given a workplace move (National Statistics, 2002). Note that in the GSOEP survey analysed here, there is no information whether firms move. However, by keeping employer and residence given, we infer that all changes in commuting distance are caused by a (exogenous) change in commuting distance as a result of a relocation of the workplace by the firm. Note that measurement error may be important here. In particular, it is quite common that workers report a commuting distance of, let's say, $63 \mathrm{~km}$ and next year a distance of $62 \mathrm{~km}$. The change is most likely due to measurement error. In our data, $51 \%$ of all observations (when we keep residence and employer constant) indicate a change in commuting distance, but the proportion drops to $13.4 \%(6.2 \%)$ when we consider changes in distance that exceed $2 \mathrm{~km}(5 \mathrm{~km})$. This suggests that in our data, about $10 \%$ of changes in commuting distance are employer-induced, whereas the other changes are due to endogenous residence and job moves. Note that measurement error may be quite frequent, but it is quite small relative to the average commuting distance. Since we include the logarithm of commuting distance in the analysis, the (downward) bias in our estimates is likely small. Nevertheless, it is important to keep in mind that our estimates may be conservative.

We will now discuss the specification of the wage rate that must be included as a control

workers after they have changed residence or employer is then not employed, which makes the latter estimation method less efficient.

${ }^{26}$ If measurement errors are white noise, it implies that our results are biased towards zero and therefore conservative (so, the true values are larger in magnitude). 
variable in (5) according to theory. ${ }^{27}$ Net hourly wage rates are calculated by dividing net monthly earnings by monthly hours. Such a calculation introduces a form of measurement error, known as 'division bias', because measurement error in hours enters both the left and right handsight of (5). ${ }^{28}$ This results in a spurious negative correlation between hours and the wage rate (Stewart and Swaffield, 1997; Lee, 2001), because overreporting of hours would lead to an underreporting of the hourly wage rate. ${ }^{29}$ So, we calculate the wage rate using contractual hours instead of observed hours, because the division bias in hourly wage rates using contractual hours is substantially less than using observed hours. Another problem with estimating the wage elasticity in (5) is, according to some studies, the endogeneity of earnings, because of uncontrolled wealth effects (e.g. the arrival of new information about the wage rate may also lead to a revision in expected lifetime wealth, which is captured by the error term $v_{i t}$; see MaCurdy, 1981; Altonji, 1986). A valid estimation of the wage elasticity, taking these two sources of endogeneity into account, is to instrument changes in the wage rate. We instrument the change in wage rate using age and its square. ${ }^{30}$ These instruments are frequently used in the labour supply literature and are usually thought to be exogenous with respect to change in labour supply (see e.g. MaCurdy, 1981; Lee, 2001). ${ }^{31}$ As shown in Table B3, these instruments are strong. $^{32}$

\footnotetext{
${ }^{27}$ Note however that it turns out not to be necessary to control for wages in estimating the commuting distance elasticity. This is in line with studies that show that the correlation between commuting distance and wages is low (e.g. Manning, 2003).

${ }^{28}$ Note that random measurement error in labour supply does not affect the consistency of the estimates, because the measurement error is in the dependent variable.

${ }^{29}$ The importance of wage division bias has been widely documented in the labour supply literature (e.g. Borjas, 1979; Abowd and Card, 1989; Lee, 2001; French, 2004).

${ }^{30}$ A non-linear specification of age is appropriate, because one expects that older individuals are less likely to receive a wage increase, but one would expect this effect to decrease after a certain age.

${ }^{31}$ Note however that it is possible that changes in worker preferences for labour supply are related to age, in which case age is invalid as an instrumental variable for wage rate in estimating (5). Consequently, the estimated wage elasticity is likely to be downward bias (Altonji, 1986). Further, note that we indirectly take into account the individual's decision to participate or not in the labour market, because we take differences for each employed individual.

32 The effect of our instruments of wage rate growth is as expected and is in line with the literature, as age has a negative effect on wage growth (see Table B3). Although according static labour supply theory as used in this paper, commuting distance should not be included as a control in the instrumentation of wage rate, job search theory indicates that, generally, the wage rate will depend positively on commuting distance (Manning, 2003).
} 


\subsection{Empirical results}

The econometric results of all models taking first-differences (5) are shown in Table $2 .{ }^{33}$ Since both the labour supply variable and commuting distance are in logarithmic form, the commuting distance elasticity of labour supply is given by the coefficient of the commuting distance variable.

The first three columns of Table 2 show the results for weekly labour supply. The effect of commuting distance on weekly labour supply is positive and statistically significant (at 5\% level). The elasticity estimate is about 0.013 (s.e. 0.002). This indicates, for example, that if the commuting distance increases from 20 to 40 kilometres, individuals increase labour supply by about 20 minutes per week. Controlling for time-varying variables (columns 2 and 3) does not appear to be essential, because the estimated effect of commuting distance on weekly labour supply not controlling for any other variable (column 1) generates almost identical results. ${ }^{34} \mathrm{We}$ have experimented with other specifications for commuting distance (e.g. controlling for workplace location within the municipality of residence), but results are very similar. For example, given a linear specification of distance, the point estimate is 0.001 (s.e. is 0.0001 ), which corresponds to an elasticity of 0.015 (evaluated at the mean commuting distance of 15.42 $\mathrm{km}$ ), which is slightly higher than the 0.013 given a logarithmic specification of distance, so essentially the same results are obtained. ${ }^{35}$

Our theoretical model assumes that labour supply patterns (hours and days worked) are optimally chosen, which may not be true for every worker. ${ }^{36}$ We therefore have also analysed the effect of commuting distance on preferred weekly labour supply (see Table 2). The effect of distance on preferred weekly labour supply (0.008 with a s.e. of 0.002$)$ overlaps with the

\footnotetext{
${ }^{33}$ We have also estimated fixed-effects models (instead of first-differences models) and obtained similar results, but the instrumentation of the wage is more complicated in that setting, so we prefer the first-differences results.

${ }^{34}$ Other estimates are as expected: the individual's labour supply decreases with other household income, having children also brings out a negative effect on labour supply, especially by women.

${ }^{35}$ Note that our wage elasticity is 0.085 in line with those assumed by Parry and Bento (2001). The authors assume that uncompensated wage elasticities are between 0.05 and 0.35 .

${ }^{36}$ For example, workers may face restrictions on hours and days worked by employers (e.g. Ilmakunnas and Pudney, 1990; Dickens and Lundberg, 1993; Stewart and Swaffield, 1997; Euwals and van Soest, 1999; for Germany see e.g. Holst and Schupp, 1998; Wolf, 1998). These studies combine information on preferred labour supply with information on observed hours to identify restrictions on hours.
} 
confidence interval, at five percent level, of the above reported effect on the observed labour supply. To the extent that the point estimate of distance on the preferred labour supply is less than the observed hours suggests that our results may partially be the consequence of employer restrictions on the number of hours. ${ }^{37}$ We have also estimated the effect of commuting distance on the difference between preferred and observed weekly labour supply. The estimate of distance on the difference between the preferred and the observed labour supply is -0.005 with a s.e. of 0.003 , consistent with the results in Table 2 .

Columns 7 and 10 of Table 2 show the results of time-varying explanatory variables on number of workdays and daily hours. In line with the theoretical model developed, we find a positive elasticity of daily hours with commuting distance $(0.013$ with a s.e. of 0.002$)$. This elasticity of daily hours with commuting distance is essentially the same as the elasticity of weekly hours. Workers with long commute distances, ceteris paribus, appear to increase the total labour supply mainly by increasing their daily labour supply. The theoretical model developed offers little insight into the expected effect of commuting distance on workdays. We estimate an insignificant elasticity of workdays with commuting distance $(0.003$ with a s.e. of 0.002$)$.

Columns 8 and 11 of Table 2 show the results for workdays and daily hours controlling for weekly labour supply. This is useful as an additional test of the model. In line with our theoretical model, we find, when controlling for weekly hours, a positive effect of distance on daily labour supply with an elasticity of 0.004 (s.e. of 0.001 ), and a negative effect on the number of workdays with an elasticity of -0.004 (s.e. of 0.001 ).

One statistical difficulty when controlling for weekly labour supply is the possible endogeneity of weekly labour supply (as workers are likely heterogeneous in their preference for leisure time). We therefore instrument the worker's weekly labour supply with other household income, defined as the total household income minus the worker's own-labour income, (for the first step see Table B4; the instrument appears to be sufficiently strong) and show the results in

\footnotetext{
${ }^{37}$ Note however that the question about preferred labour supply is slightly ambiguous, so that it may not specifically be related to the current job.
} 
columns 9 and 12 of Table 2. We find the same estimates as the ones when the endogeneity of weekly labour supply is not corrected for though the standard errors are larger.

\subsection{Sensitivity analysis}

We have also investigated whether it is useful to distinguish between male and female workers, because it seems plausible that the effect of changes in commuting distance is gender-specific as

it depends on the labour market state of the spouse, presence of children, etc. We find a commuting distance elasticity of weekly hours of 0.009 (s.e. is 0.002 ) for male workers, which is half the size of the one obtained for female workers of 0.016 (s.e. is 0.003 ), see Table B5. Estimates for workdays and daily hours also suggest that the effect of commuting distance on labour supply patterns is stronger for female workers, but the instruments are not strong enough for proper interpretation. We have also re-estimated models excluding observations that most likely refer to measurement error in the commuting distance (changes less than $2 \mathrm{~km}$ ), but the results remain robust.

\section{Conclusion}

This paper analyses the effect of costs of commuting, measured by the commuting distance, on labour supply patterns using the socio-economic panel data for Germany between 1997 and 2007. As far as we are aware, theoretical and empirical work that focuses on how daily hours respond to changes in commuting distance has been analysed here for the first time. We deal with the endogeneity of commuting distance by means of a worker first-differences approach for a sample of employer-induced changes in commuting distance (which are result of firm/workplace relocation). Although one may have intuitive feelings about the effects of commuting distance on total labour supply, the theoretical model developed in this paper demonstrates that empirical analysis is needed, as it is not clear what the direction of the effect is in reality. 
In the current paper, we have emphasized the importance of the assumptions regarding modelled labour supply patters. In particular, how workers may choose their daily labour supply as well as number of workdays are fundamental assumptions.

Our empirical results show a slight positive effect of commuting distance on weekly labour supply. This effect is the combination of a positive effect on daily hours and a smaller (negative) effect on number of workdays. These results are in contrast to assumptions in the literature (see e.g. Parry and Bento, 2001; Calthrop, 2001). The main implication of our results is that when introducing a road tax, a budget-neutral reduction in the income tax, as advocated in the literature (Parry and Bento, 2001; Mayeres and Proost, 2001), may not be necessary in order to increase welfare. Note however that our results need to be interpreted with some caution, because we focus on employed workers only and do not consider the effect of changes in commuting costs/time on labour market participation. ${ }^{38}$

The estimated positive effect of distance is consistent with the model developed. It is however also consistent with other explanations. One other explanation may be that workers may reduce commuting costs by leaving earlier from home or departing later from work in line with bottleneck economic models (Vickrey, 1969; Arnott et al., 1993). When individuals leave earlier from home or depart later from work (e.g. workers with fixed work schedules), they simultaneously increase labour supply, when the number of workdays remains constant. We hope to examine this possibility in the near future.

\footnotetext{
${ }^{38}$ However, there are reasons to believe that commuting costs, and therefore road pricing, may have little or no effect on the participation decision. One reason is that female workers for whom the participation decision is strongest affected by economic incentives, do not belong to the same group of workers who generally will face a road tax. The percentage of women that commute a long distance and work a few hours is usually low. Men usually work full-time and commute longer distances. Female workers with few hours of work are less likely to travel by car and have shorter commuting distances if they travel by car.
} 


\section{References}

Abowd, J. and Card, D. (1989). 'On the covariance structure of earnings and hours changes', Econometrica, vol. 57(2) (March), pp. 411-45.

Altonji, J. G. (1986). 'Intertemporal substitution in labor supply: evidence from Micro Data', Journal of Political Economy, vol. 94(3) (June), pp. 176-215.

Arnott, R., de Palma, A. and Lindsey, R. (1993). 'A structural model of peak-period congestion: a traffic bottleneck with elastic demand', The American Economic Review, vol. 83(1) (March), pp. 161-79.

Arnott, R., Tilman, R. and Schöb, R. (2005). Alleviating Urban Traffic Congestion, Cambridge, MA: MIT Press.

Bell, L. A. and Freeman, R. B. (2001). 'The incentive for working hard: explaining hours worked differences in the US and Germany', Labour Economics, vol. 8(2) (May), pp. 181202.

Blank, R. M. (1988). 'Simultaneously modeling the supply of weeks and hours of work among female household heads', Journal of Labor Economics, vol. 6(2) (April), pp. 177-204.

Borjas, G. J. (1980). 'The relationship between wages and weekly hours of work: the role of division bias', The Journal of Human Resources, vol. 15(3) (Summer), pp. 409-23.

Bovenberg, A. L. and Goulder, L. H. (1996). 'Optimal environmental taxation in the presence of other taxes: general equilibrium analysis', American Economic Review, vol. 86(4) (September), pp. $985-1000$.

Calthrop, E. (2001). 'Essays in urban transport economics', Katholieke Universiteit Leuven (dissertation).

Cogan, J. F. (1981). 'Fixed costs and labor supply’, Econometrica, vol. 49(4) (July), pp. 945-63.

Costa, D. L. (2000). 'The wage and the length of the work day: from the 1980s to 1991', Journal of Labor Economics, vol. 18(1) (January), pp. 156-81. 
De Borger, B. and van Dender, K. (2003). 'Transport tax reform, commuting, and endogenous values of time', Journal of Urban Economics, vol. 53(3) (May), pp. 510-30.

Dickens, W. and Lundberg, S. (1993). 'Hours restrictions and labor supply', International Economic Review, vol. 34(1) (February), pp. 169-92.

Ehrenberg, R. G. and Smith, R. S. (2003). Modern Labor economics: Theory and public policy, Boston, MS: Pearson.

Euwals, R. van Soest, A. (1999). 'Desired and actual labor supply of unmarried men and women in the Netherlands', Labour Economics, vol. 6(1) (March), pp. 95-118.

French, E. (2004). 'The labor supply response to (mismeasured but) predictable wage changes', The Review of Economics and Statistics, vol. 86(2) (May), pp. 602-13.

Gubits, D. B. (2004). Commuting, Work Hours, and the Metropolitan Labor Supply Gradient, Mimeo.

Hamermesh, D. S. (1996). Workdays, Workhours and Work Schedules: Evidence for the United States and Germany, Kalamazoo, MI: W. E. Upjohn Institute.

Hanoch, G. (1980). 'Hours and weeks in the theory of labor supply', Female Labor Supply: Theory and Estimation, James Smith (ed.), Princenton, N.J.: Princenton University Press.

Heckman, J.S. (1980). 'Income, labor supply and urban residence', American Economic Review, vol. 70(4) (September), pp. 805-11.

Holst, E. and Schupp, J. (1998). 'Arbeitszeitpräferenzen in West- und Ostdeutschland 1997', DIW-Wochenbericht, vol. 37.

Ilmakunnas, S. and Pudney, S. (1990). 'A model of female labour supply in the presence of hours restrictions', Journal of Public Economics, vol. 41(2) (March), pp. 66-100.

Lee, C. (2001). 'Finite sample bias in IV estimation of intertemporal labor supply models: is the intertemporal substitution elasticity really small?', The Review of Economics and Statistics, vol. 83(4) (November), pp. 638-46. 
MaCurdy, T. E. (1981). ‘An empirical model of labor supply in a life-cycle setting', The Journal of Political Economy, vol. 89(6) (December), pp. 1059-85.

Manning, A. (2003). 'The real thin theory: monopsony in modern labour markets', Labour Economics, vol. 10(2) (April), pp. 105-31.

Mayeres, I. and Proost, S. (2001). 'Marginal tax reform, externalities and income distribution', Journal of Public Economics, vol. 79(2) (February), pp. 343-63.

National Statistics (2002). Labour Force Survey LFS 2002, Newport, Great Britain.

Ostner, I., Reif, M., Turba, H. and Schmitt, C. (2003). Labour supply in Germany before and since unification, National report for the project Welfare Policies and Employment in the Context of Family Change.

Parry, I. W. H. and Bento, A. (2001). 'Revenue recycling and the welfare effects of road pricing', Scandinavian Journal of Economics, vol. 103(4) (December), pp. 645-71.

Small, K. A. and Verhoef, E. T. (2007). The Economics of Urban Transportation, London \& New York: Routledge.

Stewart, M. B. and Swaffield, J. K. (1997). 'Constraints on the desired hours of work of British men', The Economic Journal, vol. 107(441) (March), pp. 520-35.

Van Ommeren, J. N. and Fosgerau, M. (2009). 'The workers' marginal costs of commuting: a search and mobility approach', Journal of Urban Economics, vol. 65(1) (January), pp. 38-47.

Varian, H. R. (1992). Microeconomic Analysis, $3^{\text {rd }}$ edition, New York: WW Norton and Company.

Vickrey, W. S. (1969). 'Congestion theory and transport investment', American Economic Review (Papers and Proceedings), vol. 59(2) (May), pp. 251-60.

Wales, T. J. (1978). 'Labour supply and commuting time: an empirical study', Journal of Econometrics, vol. 8(2) (October), pp. 215-26.

Weltevreden, J. W. J., van Oort, F. G., van Vliet, J., Pellenbarg, P. H., Hans van Amsterdam, H. and Traa, M. R. M. J. (2007). 'Firm relocation and regional employment development in the Netherlands (1999-2006)', European Regional Science Association. 
White, M. J. (1988). 'Location choice and commuting behaviour in cities with decentralized employment', Journal of Urban Economics, vol. 24(2) (September), pp. 129-52.

Wolf, E. (1998). Do Hours Restrictions Matter? A Discrete Family Labor Supply Model with Endogenous Wages and Hours Restrictions, Center for European Research (ZEW) Discussion Paper 98-44, Mannheim.

Wuyts, B. (2009). 'Essays on congestion, transport taxes, and the labour market', Universiteit Antwerpen (dissertation).

Zax, J. S. (1991). 'The substitution between moves and quits', The Economic Journal, vol. 101(409) (November), pp. 1510-21.

Zax, J. S. and Kain, J. F. (1996). 'Moving to the suburbs: do relocating companies leave their black employees behind?', Journal of Labor Economics, vol. 14(3) (July), pp. 472-504. 
Table 1. Effects of Commuting Cots on Labour Supply

\begin{tabular}{lllll}
\hline & & Daily hours & Workdays & $\begin{array}{l}\text { Total labour } \\
\text { supply }\end{array}$ \\
\hline \multirow{2}{*}{ Labour model (e.g. Gubits, 2004) } & Time costs & - & Fixed & - \\
& Monetary costs & + & Fixed & + \\
\hline \multirow{2}{*}{ Transport model (e.g. Parry and Bento) } & Time costs & Fixed & - & - \\
& Monetary costs & Fixed & $+/-$ & $+/-$ \\
\hline \multirow{2}{*}{ Current paper } & Time costs & + & - & $+/-$ \\
& Monetary costs & + & $+/-$ & $+/-$ \\
\hline
\end{tabular}

Note $:+=$ positive $;-=$ negative $;+-=$ ambiguous 
Table 2. Estimates of Logarithm of Changes in Labour Supply with Changes in Commuting Distance (1997-2007 GSOEP)

\begin{tabular}{|c|c|c|c|c|c|c|c|c|c|c|c|c|}
\hline & {$[1]$} & {$[2]$} & [3] & {$[4]$} & {$[5]$} & {$[6]$} & [7] & {$[8]$} & [9] & {$[10]$} & [11] & [12] \\
\hline & \multicolumn{3}{|c|}{$\begin{array}{c}\text { Observed weekly labour supply } \\
\text { (in } \log \text { ) }\end{array}$} & \multicolumn{3}{|c|}{$\begin{array}{c}\text { Preferred weekly labour supply } \\
\text { (in } \log \text { ) }\end{array}$} & \multicolumn{3}{|c|}{ Workdays per week (in log) } & \multicolumn{3}{|c|}{ Daily hours (in log) } \\
\hline $\begin{array}{l}\text { Commuting distance in } \\
\text { log (in km) } \\
\text { Weekly labour supply } \\
\text { in log }\end{array}$ & $\begin{array}{l}0.012 \\
(0.002)^{* *}\end{array}$ & $\begin{array}{l}0.013 \\
(0.002)^{* *}\end{array}$ & $\begin{array}{l}0.013 \\
(0.002)^{* *}\end{array}$ & $\begin{array}{l}0.008 \\
(0.002)^{* *}\end{array}$ & $\begin{array}{l}0.008 \\
(0.002)^{* *}\end{array}$ & $\begin{array}{l}0.008 \\
(0.002)^{* *}\end{array}$ & $\begin{array}{l}0.003 \\
(0.002)\end{array}$ & $\begin{array}{l}-0.004 \\
(0.001)^{* *} \\
0.416 \\
(0.011)^{* *}\end{array}$ & $\begin{array}{l}-0.004 \\
(0.003) \\
0.539 \\
(0.220)^{* *}\end{array}$ & $\begin{array}{l}0.013 \\
(0.002)^{* *}\end{array}$ & $\begin{array}{l}0.004 \\
(0.001)^{* *} \\
0.584 \\
(0.011)^{* *}\end{array}$ & $\begin{array}{l}0.005 \\
(0.004) \\
0.625 \\
(0.264)\end{array}$ \\
\hline $\begin{array}{l}\text { Net hourly wage rate in } \\
\log \text { (in euros) }\end{array}$ & & $\begin{array}{l}0.085 \\
(0.031)^{* *}\end{array}$ & & & $\begin{array}{l}0.004 \\
(0.036)\end{array}$ & & $\begin{array}{l}0.040 \\
(0.025)\end{array}$ & $\begin{array}{l}0.012 \\
(0.018)\end{array}$ & $\begin{array}{l}0.040 \\
(0.025)\end{array}$ & $\begin{array}{l}0.029 \\
(0.030)\end{array}$ & $\begin{array}{l}-0.011 \\
(0.018)\end{array}$ & $\begin{array}{l}0.029 \\
(0.030)\end{array}$ \\
\hline $\begin{array}{l}\text { Employment region - } \\
\text { new federal states }\end{array}$ & & $\begin{array}{l}-0.010 \\
(0.004)^{* *}\end{array}$ & $\begin{array}{l}-0.009 \\
(0.004)^{* * *}\end{array}$ & & $\begin{array}{l}-0.004 \\
(0.004)\end{array}$ & $\begin{array}{l}-0.003 \\
(0.004)\end{array}$ & $\begin{array}{l}-0.006 \\
(0.005)\end{array}$ & $\begin{array}{l}0.002 \\
(0.004)\end{array}$ & $\begin{array}{l}-0.002 \\
(0.005)\end{array}$ & $\begin{array}{l}-0.014 \\
(0.006)^{* *}\end{array}$ & $\begin{array}{l}-0.002 \\
(0.004)\end{array}$ & $\begin{array}{l}-0.009 \\
(0.006)\end{array}$ \\
\hline $\begin{array}{l}\text { Other household } \\
\text { income/10 }\end{array}$ & & $\begin{array}{l}-0.047 \\
(0.013)^{* *}\end{array}$ & $\begin{array}{l}-0.057 \\
(0.012)^{\text {** }}\end{array}$ & & $\begin{array}{l}-0.025 \\
(0.015)\end{array}$ & $\begin{array}{l}-0.026 \\
(0.014)^{*}\end{array}$ & $\begin{array}{l}-0.029 \\
(0.012)^{* *}\end{array}$ & $\begin{array}{l}-0.003 \\
(0.009)\end{array}$ & & $\begin{array}{l}-0.034 \\
(0.014)^{* *}\end{array}$ & $\begin{array}{l}0.003 \\
(0.009)\end{array}$ & \\
\hline $\begin{array}{l}\text { Female } \times \text { number of } \\
\text { children }\end{array}$ & & $\begin{array}{l}-0.066 \\
(0.005)^{* *}\end{array}$ & $\begin{array}{l}-0.066 \\
(0.005)^{* *}\end{array}$ & & $\begin{array}{l}-0.061 \\
(0.006)^{* *}\end{array}$ & $\begin{array}{l}-0.061 \\
(0.006)^{* *}\end{array}$ & $\begin{array}{l}-0.030 \\
(0.004)^{* *}\end{array}$ & $\begin{array}{l}-0.006 \\
(0.003)^{*}\end{array}$ & $\begin{array}{l}0.005 \\
(0.015)\end{array}$ & $\begin{array}{l}-0.028 \\
(0.005)^{* *}\end{array}$ & $\begin{array}{l}0.006 \\
(0.003)^{*}\end{array}$ & $\begin{array}{l}0.013 \\
(0.018)\end{array}$ \\
\hline Child dummy & & $\begin{array}{l}-0.023 \\
(0.005)^{* *}\end{array}$ & $\begin{array}{l}-0.021 \\
(0.005)^{\text {*** }}\end{array}$ & & $\begin{array}{l}-0.012 \\
(0.006)^{*}\end{array}$ & $\begin{array}{l}-0.011 \\
(0.006)^{*}\end{array}$ & $\begin{array}{l}-0.016 \\
(0.005)^{* *}\end{array}$ & $\begin{array}{l}-0.001 \\
(0.003)\end{array}$ & $\begin{array}{l}-0.005 \\
(0.006)\end{array}$ & $\begin{array}{l}-0.021 \\
(0.005)^{* *}\end{array}$ & $\begin{array}{l}0.001 \\
(0.003)\end{array}$ & $\begin{array}{l}-0.008 \\
(0.008)\end{array}$ \\
\hline $\begin{array}{l}\text { Number of household } \\
\text { members }\end{array}$ & & $\begin{array}{l}-0.008 \\
(0.002)^{* *}\end{array}$ & $\begin{array}{l}-0.009 \\
(0.002)^{\text {*** }}\end{array}$ & & $\begin{array}{l}-0.008 \\
(0.003)^{\text {** }}\end{array}$ & $\begin{array}{l}-0.008 \\
(0.003)^{\text {** }}\end{array}$ & $\begin{array}{l}-0.002 \\
(0.002)\end{array}$ & $\begin{array}{l}-0.001 \\
(0.001)\end{array}$ & $\begin{array}{l}0.002 \\
(0.003)\end{array}$ & $\begin{array}{l}-0.001 \\
(0.002)\end{array}$ & $\begin{array}{l}0.001 \\
(0.001)\end{array}$ & $\begin{array}{l}0.005 \\
(0.003)\end{array}$ \\
\hline Year controls & Included & Included & Included & Included & Included & Included & Included & Included & Included & Included & Included & Included \\
\hline Adjusted R-squared & 0.001 & 0.010 & 0.011 & 0.000 & 0.006 & 0.006 & 0.007 & 0.407 & 0.007 & 0.007 & 0.586 & 0.007 \\
\hline No. observations & 43,694 & 43,694 & 43,694 & 35,264 & 35,264 & 35,264 & 20,558 & 20,558 & 20,558 & 20,558 & 20,558 & 20,558 \\
\hline
\end{tabular}

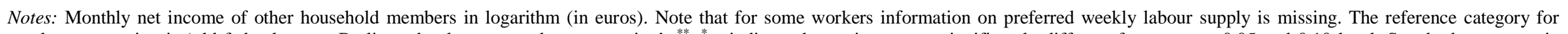

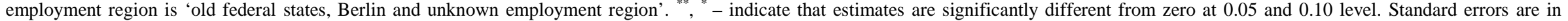
parentheses. Weekly labour supply in columns [9] and [12] is instrumented following the IV procedure of Table B5. 


\section{Appendix A: Comparative Statics}

In this appendix, we label $F_{1}$ and $F_{2}$ as the two first-order conditions (1) and (2) of the worker's optimization problem for $H$ and $D$. The Hessian matrix $M$ of the first-order conditions can written as:

$$
M=\left[\begin{array}{ll}
\frac{\partial F_{1}}{\partial H} & \frac{\partial F_{1}}{\partial D} \\
\frac{\partial F_{2}}{\partial H} & \frac{\partial F_{2}}{\partial D}
\end{array}\right],
$$

where:

$$
\begin{aligned}
& \frac{\partial F_{1}}{\partial H}=V_{Y} w^{\prime \prime}(H) D+V_{Y Y}\left[w^{\prime}(H) D\right]^{2}-V_{Y L} w^{\prime}(H) D^{2}-V_{L Y} w^{\prime}(H) D^{2}+V_{L L} D^{2}<0, \\
& \frac{\partial F_{1}}{\partial D}=V_{Y} w^{\prime}(H)-V_{L}+D w^{\prime}(H)\left[V_{Y Y}[w(H)-k c]-V_{L Y}[H+t]\right]-V_{L Y}[w(H)-k c] D+V_{L L} D[H+t]<0, \\
& \frac{\partial F_{2}}{\partial H}=V_{Y} w^{\prime}(H)-V_{L}+[w(H)-k c] D\left[V_{Y Y} w^{\prime}(H)-V_{Y L}\right]-V_{L Y} w^{\prime}(H) D[H+t]+V_{L L} D[H+t]<0, \\
& \frac{\partial F_{2}}{\partial D}=V_{Y Y}[w(H)-k c]^{2}-V_{Y L}[w(H)-k c][H+t]-V_{L Y}[w(H)-k c][H+t]+V_{L L}[H+t]^{2}<0 .
\end{aligned}
$$

Substituting (3) into these equations implies the sign of the derivatives. The determinant of $M$ is negative given concavity of the utility function $v$, concavity of $w(H)$ and expression (3), so the first-order conditions imply a global maximum.

Application of Cramer's rule yields the partial effects of $q$ on $H$ and $D$, for $q=t, k c$ :

$$
\frac{\partial H}{\partial q}=\frac{\left|\begin{array}{ll}
-\frac{\partial F_{1}}{\partial q} & \frac{\partial F_{1}}{\partial D} \\
-\frac{\partial F_{2}}{\partial q} & \frac{\partial F_{2}}{\partial D}
\end{array}\right|}{\left|\begin{array}{ll}
\frac{\partial F_{1}}{\partial H} & \frac{\partial F_{1}}{\partial D} \\
\frac{\partial F_{2}}{\partial H} & \frac{\partial F_{2}}{\partial D}
\end{array}\right|}>0
$$


and

$$
\frac{\partial D}{\partial q}=\frac{\left|\begin{array}{ll}
\frac{\partial F_{1}}{\partial H} & -\frac{\partial F_{1}}{\partial q} \\
\frac{\partial F_{2}}{\partial H} & -\frac{\partial F_{2}}{\partial q}
\end{array}\right|}{\left|\begin{array}{ll}
\frac{\partial F_{1}}{\partial H} & \frac{\partial F_{1}}{\partial D} \\
\frac{\partial F_{2}}{\partial H} & \frac{\partial F_{2}}{\partial D}
\end{array}\right|}
$$

where:

$$
\begin{aligned}
& \frac{\partial F_{1}}{\partial t}=-V_{Y L} w^{\prime}(H) D^{2}+V_{L L} D^{2}<0, \\
& \frac{\partial F_{1}}{\partial(k c)}=-V_{Y Y} w^{\prime}(H) D^{2}+V_{L Y} D^{2}>0, \\
& \frac{\partial F_{2}}{\partial t}=-V_{Y L}[w(H)-k c] D-V_{L}+V_{L L}[H+t] D<0, \\
& \frac{\partial F_{2}}{\partial(k c)}=-V_{Y}-V_{Y Y}[w(H)-k c] D+V_{L Y}[H+t] D<>0,
\end{aligned}
$$

where the sign of the last derivative is ambiguous given the concavity of the utility function $v$ and concavity of $w(H)$.

\section{A.1. Partial effect of commuting time and monetary commuting costs on workdays}

The effect of commuting time $t$ on workdays $D$ is determined by totally differentiating $F_{2}$ with $t$, and putting this expression equal to zero. Then, $\partial D / \partial t$ can be expressed by:

$$
\frac{\partial D}{\partial t}=\frac{V_{Y L} D w^{\prime}(H)-\frac{\partial H}{\partial t}\left[V_{Y} w^{\prime \prime}(H)+w^{\prime}(H)\left\{V_{Y Y} D w^{\prime}(H)-V_{Y L} D\right\}-V_{Y L} D w^{\prime}(H)+V_{L L} D\right]}{w^{\prime}(H)\left\{V_{Y Y} w(H)-V_{Y L}(H+t)\right\}-V_{L Y} w(H)+V_{L L}(H+t)}<0,
$$

where the inequality in this expression follows from the concavity of the utility function $v$, concavity of $w(H)$ and $\partial H / \partial t$. The denominator in this expression is negative, whereas the numerator is positive, then the sign of the partial effect of time on workdays $\partial D / \partial t$ is unambiguously determined and is negative. 
To see the effect of $k c$ on $D$, it is more straightforward to focus on A2. Carrying out the calculation of the determinant in $\mathrm{A} 2$, the sign of $\partial D / \partial(k c)$ is indeterminate, depending on the size of $V_{Y}$. If $V_{Y} \rightarrow \infty$, then $\partial F_{2} / \partial(k c)<0, \quad$ so $\partial D / \partial(k c)<0$. In contrast, if $V_{Y} \rightarrow 0$, then $\partial F_{2} / \partial(k c)>0$, so $\partial D / \partial(k c)>0$.

\section{A.2. Partial effect of commuting time and monetary commuting costs on total labour supply}

The effect of $k c$ on total labour supply can be shown to be ambiguous (as the effect of $k c$ on $D$ is ambiguous). Full results can be received upon request. More interestingly is the effect of $t$ on total labour supply, which can be written as $\partial(H D) / \partial t=H \partial D / \partial t+D \partial H / \partial t$, where $+/$ - under the $+$

terms refer to whether the term is positive or negative. Substituting (A1) and (A2) into this

expression we obtain: $\operatorname{sign}\left(\frac{\partial(H D)}{\partial t}\right)=\operatorname{sign}\left(H\left[-\frac{\partial F_{1}}{\partial H} \frac{\partial F_{2}}{\partial t}+\frac{\partial F_{2}}{\partial H} \frac{\partial F_{1}}{\partial t}\right]+D\left[-\frac{\partial F_{2}}{\partial D} \frac{\partial F_{1}}{\partial t}+\frac{\partial F_{1}}{\partial D} \frac{\partial F_{2}}{\partial t}\right]\right)$.

The sign of $\partial(D H) / \partial t$ is positive or negative depending on the numerical values of $V_{Y Y}, V_{L L}$ and $V_{Y L}$. To see the ambiguity of the effect of $t$ on $D H$ more clearly, let us concentrate on the case that $V_{Y L}=0$ and $V_{L L}$ is close to zero, so $V_{L L}$ can be ignored. The sign of the effect of $t$ on total labour supply can then be written as:

$$
\operatorname{sign}\left(\frac{\partial(D H)}{\partial t}\right)=\operatorname{sign}\left(\frac{\partial F_{2}}{\partial t}\left[-V_{Y} w^{\prime \prime}(H)+V_{Y Y} w^{\prime}(H)^{2} t\right]\right),
$$

where the sign of the terms between square brackets in expression (A3) follows from the concavity of $w(H)$ and the concavity of the utility function $v$. The terms between square brackets consist of two components: the first component is positive, whereas the second one is negative. The first component reflects the reduction in the marginal daily wage as a result of increasing the number of daily hours. The second component reflects the decrease in marginal utility of income and is negative because the decrease in number of daily hours. 
We can also see the above ambiguity by concentrating on the case that $V_{Y L}=0$ and $V_{Y Y}$ is close to zero, so $V_{Y Y}$ can be ignored. The effect of $t$ on total labour supply can now be written as:

$$
\operatorname{sign}\left(\frac{\partial(D H)}{\partial t}\right)=\operatorname{sign}\left(V_{Y} w^{\prime \prime}(H) H[H+t]+V_{L} t\right),
$$

where the sign is again ambiguous. Expression (A4) consists of two components: the first component is negative, whereas the second one is positive. The first component reflects the reduction in the marginal daily wage as a result of increasing the number of daily hours. The second component is the marginal utility of leisure time times the time costs of commuting.

Overall, the effect of $t$ on $D H$ is positively only if the effect of $t$ on daily hours is relatively large, such that the marginal utility of leisure is relatively small or the reduction in marginal daily wage is relatively large.

\section{A.3. Partial effect of distance keeping speed constant}

The partial effects of commuting distance keeping speed constant on $H$ and $D$ can be solved using Cramer's rule and the following two derivatives:

$$
\begin{aligned}
& \frac{\partial F_{1}}{\partial k \mid s}=-V_{Y Y} w^{\prime}(H) D^{2} c-V_{Y L} w^{\prime}(H) D^{2} / s+V_{L Y} D^{2} c+V_{L L} D^{2} / s<>, \\
& \frac{\partial F_{2}}{\partial k \mid s}=-V_{Y} c-[w(H)-k c] D\left[V_{Y Y} c+V_{Y L} / s\right]-V_{L} / s+V_{L Y}[H+k / s] D c+V_{L L}[H+k / s] D / s<>0,
\end{aligned}
$$

where $\mid s$ denotes conditional on speed, but not conditional on commuting time. The sign of these derivatives is ambiguous because time and commuting costs have opposite effects on $F_{1}$ and $F_{2}$. The sign of $\partial H / \partial k$ is unambiguously determinate and is positive $\left(\partial H /\left.\partial k\right|_{s}=-\left[s c+w^{\prime}(H)\right]^{2}\left[H w^{\prime \prime}(H) s c[s c+w(H) H]\right]^{-1}>0\right)$, whereas the sign of $\partial D / \partial k$ is indeterminate, depending on the size of $V_{Y Y}$ and whether $[w(H)-k c] s^{-1} \leq / \geq[H+t] c$. If $V_{Y Y} \rightarrow 0$ and $[w(H)-k c] s^{-1} \geq[H+t] c$, then $\partial F_{2} / \partial k<0$, so $\partial D / \partial k<0$. In contrast, if $V_{Y Y} \rightarrow-\infty$ and 
$[w(H)-k c] s^{-1} \leq[H+t] c$, then $\partial F_{2} / \partial(k c)>0$, so $\partial D / \partial(k c)>0$. The effect of $k$ on $D H$ is again ambiguous. 


\section{Appendix B: Tables}

Table B1. Distribution of Daily Hours and Workdays per Week (Percent) (1997, 1999-2000, 2002, 2004-2007

GSOEP)

\begin{tabular}{|c|c|c|c|c|}
\hline \multirow[b]{3}{*}{ Daily hours } & \multicolumn{4}{|c|}{ Workdays per week } \\
\hline & $1-4$ & 5 & $6-7$ & All days \\
\hline & & & & \\
\hline & \multicolumn{4}{|c|}{ Workers $(\mathrm{N}=20,558)$} \\
\hline Less than or equal to $4 \mathrm{~h}$ & 1.6 & 4.0 & 0.5 & 6.1 \\
\hline More than 4 or less than $7 \mathrm{~h}$ & 2.4 & 7.9 & 1.0 & 11.3 \\
\hline Exactly 7 or less than $8 \mathrm{~h}$ & 1.0 & 13.8 & 1.0 & 15.8 \\
\hline Exactly $8 \mathrm{~h}$ & 1.2 & 31.3 & 2.0 & 34.5 \\
\hline More than 8 or less than $10 \mathrm{~h}$ & 0.7 & 18.3 & 1.4 & 20.4 \\
\hline Exactly or more than $10 \mathrm{~h}$ & 0.4 & 9.1 & 2.3 & 11.8 \\
\hline \multirow[t]{2}{*}{ All hours } & 7.3 & 84.4 & 8.2 & \\
\hline & \multicolumn{4}{|c|}{ Male workers $(\mathrm{N}=11,130)$} \\
\hline Less than or equal to $4 \mathrm{~h}$ & 0.2 & 0.2 & 0.0 & 0.4 \\
\hline More than 4 or less than $7 \mathrm{~h}$ & 0.2 & 1.1 & 0.3 & 1.6 \\
\hline Exactly 7 or less than $8 \mathrm{~h}$ & 0.4 & 15.0 & 0.9 & 16.3 \\
\hline Exactly $8 \mathrm{~h}$ & 0.4 & 37.1 & 2.6 & 40.1 \\
\hline More than 8 or less than $10 \mathrm{~h}$ & 0.3 & 22.4 & 1.8 & 24.5 \\
\hline Exactly or more than $10 \mathrm{~h}$ & 0.3 & 13.2 & 3.4 & 16.9 \\
\hline \multirow[t]{2}{*}{ All hours } & 1.8 & 89.0 & 9.0 & \\
\hline & \multicolumn{4}{|c|}{ Female workers $(\mathrm{N}=9,427)$} \\
\hline Less than or equal to $4 \mathrm{~h}$ & 3.3 & 8.6 & 1.0 & 12.9 \\
\hline More than 4 or less than $7 \mathrm{~h}$ & 5.0 & 16.1 & 1.8 & 22.9 \\
\hline Exactly 7 or less than $8 \mathrm{~h}$ & 1.6 & 12.3 & 1.1 & 15.0 \\
\hline Exactly $8 \mathrm{~h}$ & 2.1 & 24.5 & 1.4 & 28.0 \\
\hline More than 8 or less than $10 \mathrm{~h}$ & 1.2 & 13.5 & 0.9 & 15.6 \\
\hline Exactly or more than $10 \mathrm{~h}$ & 0.6 & 4.3 & 0.9 & 5.8 \\
\hline All hours & 13.8 & 79.3 & 7.1 & \\
\hline
\end{tabular}

Notes: Totals do not add to $100 \%$ because of rounding. Standard deviations are in parentheses.

Table B2. Correlations of Dimensions of Labour Supply (1997, 1999-2000, 2002, 2004-2007 GSOEP)

\begin{tabular}{lll}
\hline & Daily hours & Workdays per week \\
\hline All workers $(\mathrm{N}=20,558)$ & & \\
Workdays per week & 0.222 & \\
Weekly hours & 0.905 & 0.591 \\
\hline Male workers $(\mathrm{N}=11,130)$ & & \\
Workdays per week & 0.163 & 0.578 \\
Weekly hours & 0.890 & \\
\hline Female workers $(\mathrm{N}=9,427)$ & & \\
Workdays per week & 0.160 & 0.579 \\
Weekly hours & 0.882 & \\
\hline
\end{tabular}

Notes: Pearson correlations; all correlations are significant at 0.05 level (2-tailed). 
Table B3. First Step Results of the Logarithm of Changes in the Net Hourly Wage Rate IV Procedure (1997-2007

GSOEP)

\begin{tabular}{lccc}
\hline Variables & Workers & Male workers & Female workers \\
\hline Instruments & & & \\
Age & $-0.018(0.001)^{* *}$ & $-0.018(0.001)^{* * *}$ & $-0.019(0.001)^{* *}$ \\
Age $/ 1,000$ & $0.192(0.011)^{* *}$ & $0.186(0.014)^{* *}$ & $0.200(0.017)^{* *}$ \\
Control factors & & & $-0.004(0.031)$ \\
Change in commuting distance in log (in km)/10 & $0.011(0.020)$ & $0.025(0.026)$ & $0.004(0.006)$ \\
Change in employment region - new federal states & $0.005(0.004)$ & $0.006(0.006)$ & $-0.181(0.026)^{* *}$ \\
Change in other household income in log (in euros)/10 & $-0.108(0.014)^{* *}$ & $-0.072(0.016)^{* *}$ & $0.004(0.008)$ \\
Change in female $\times$ number of children & $-0.003(0.006)$ & & $0.002(0.012)$ \\
Change in child dummy & $0.016(0.006)^{* *}$ & $0.022(0.007)^{* *}$ & $-0.003(0.004)$ \\
Change in number of household members & $-0.005(0.002)^{*}$ & $-0.007(0.003)^{* *}$ & Included \\
\hline Year controls & Included & Included & 0.022 \\
\hline Adjusted R-squared & 0.023 & 0.025 & 20,194 \\
\hline No. observations & 43,694 & 23,499 & 24.65 \\
\hline F test & 59.79 & 39.07 & - \\
\hline
\end{tabular}

Notes: Wage rate in euros; monthly net income of other household members. The reference category for employment region is 'old federal states, Berlin and unknown employment region. ${ }^{* *},{ }^{*}-$ indicate that estimates are significantly different from zero at 0.05 and 0.10 level. Standard errors are in parentheses. 
Table B4. First Step Results of the Logarithm of Changes in Weekly Labour Supply IV Procedure (1997, 19992000, 2002, 2004-2007 GSOEP)

\begin{tabular}{ll}
\hline Variables & Workers \\
\hline Instrument & $-0.007(0.002)^{* *}$ \\
Other household income in log (in euros) & \\
Control factors & $0.015(0.003)^{* *}$ \\
Change in commuting distance in log (in km)/10 & $-0.020(0.007)^{* *}$ \\
Change in employment region - new federal states & $-0.059(0.007)^{* *}$ \\
Change in female $\times$ number of children & $-0.034(0.007)^{* *}$ \\
Change in child dummy & $-0.004(0.003)$ \\
Change in number of household members & Included \\
\hline Year controls & 0.014 \\
\hline Adjusted R-squared & 20,558 \\
No. observations & 12.25 \\
\hline F test &
\end{tabular}

Notes: Monthly net income of other household members. The reference category for employment region is 'old federal states, Berlin and unknown employment region. ${ }^{* *},{ }^{*}-$ indicate that estimates are significantly different from zero at 0.05 and 0.10 level. Standard errors are in parentheses.

Table B5. Estimates of Logarithm of Changes in Weekly Labour Supply for Male and Female Workers (1997-2007

GSOEP)

\begin{tabular}{|c|c|c|c|c|c|c|}
\hline & \multicolumn{3}{|c|}{ Male workers } & \multicolumn{3}{|c|}{ Female workers } \\
\hline & [1] & [2] & [3] & [4] & [5] & [6] \\
\hline $\begin{array}{l}\text { Commuting distance in } \log \text { (in } \\
\mathrm{km} \text { ) } / 10\end{array}$ & $\begin{array}{l}0.094 \\
(0.018)^{* *}\end{array}$ & $\begin{array}{l}0.091 \\
(0.021)^{* *}\end{array}$ & $\begin{array}{l}0.096 \\
(0.018)^{* *}\end{array}$ & $\begin{array}{l}0.147 \\
(0.030)^{* *}\end{array}$ & $\begin{array}{l}0.163 \\
(0.029)^{* *}\end{array}$ & $\begin{array}{l}0.163 \\
(0.030)^{* *}\end{array}$ \\
\hline $\begin{array}{l}\text { Net hourly wage rate in } \log \text { (in } \\
\text { euros) }\end{array}$ & & $\begin{array}{l}0.205 \\
(0.037)^{\text {** }}\end{array}$ & & & $\begin{array}{l}-0.055 \\
(0.051)\end{array}$ & \\
\hline $\begin{array}{l}\text { Employment region - new } \\
\text { federal states }\end{array}$ & & $\begin{array}{l}-0.006 \\
(0.005)\end{array}$ & $\begin{array}{l}-0.005 \\
(0.004)\end{array}$ & & $\begin{array}{l}-0.012 \\
(0.006)^{\text {*** }}\end{array}$ & $\begin{array}{l}-0.012 \\
(0.006)^{* *}\end{array}$ \\
\hline Other household income/100 & & $\begin{array}{l}-0.016 \\
(0.133)\end{array}$ & $\begin{array}{l}-0.176 \\
(0.111)\end{array}$ & & $\begin{array}{l}-1.358 \\
(0.264)^{* *}\end{array}$ & $\begin{array}{l}-1.258 \\
(0.254)^{* *}\end{array}$ \\
\hline Female $\times$ number of children $/ 10$ & & & & & $\begin{array}{l}-0.283 \\
(0.080)^{* *}\end{array}$ & $\begin{array}{l}-0.291 \\
(0.082)^{* *}\end{array}$ \\
\hline Child dummy & & $\begin{array}{l}-0.009 \\
(0.006)^{*}\end{array}$ & $\begin{array}{l}-0.002 \\
(0.005)\end{array}$ & & $\begin{array}{l}-0.081 \\
(0.011)^{* *}\end{array}$ & $\begin{array}{l}-0.081 \\
(0.011)^{* *}\end{array}$ \\
\hline Number of household members & & $\begin{array}{l}-0.002 \\
(0.003) \\
\end{array}$ & $\begin{array}{l}-0.004 \\
(0.002)^{*} \\
\end{array}$ & & $\begin{array}{l}-0.021 \\
(0.004)^{* * *}\end{array}$ & $\begin{array}{l}-0.021 \\
(0.004)^{* *}\end{array}$ \\
\hline Year controls & Included & Included & Included & Included & Included & Included \\
\hline Adjusted R-squared & 0.001 & 0.003 & 0.003 & 0.001 & 0.020 & 0.019 \\
\hline No. observations & 23,499 & 23,499 & 23,499 & 20,194 & 20,194 & 20,194 \\
\hline
\end{tabular}

Notes: Monthly net income of other household members in logarithm (in euros). The reference category for employment region is 'old federal states, Berlin and unknown employment region'. "** " - indicate that estimates are significantly different from zero at 0.05 and 0.10 level. Standard errors are in parentheses. 